\title{
Building Simulation strives for a higher impact
}

\author{
Xudong Yang ( $\square)$ \\ Editor-in-Chief \\ Department of Building Science, School of Architecture, Tsinghua University, Beijing 100084, China
}

○ Tsinghua University Press and Springer-Verlag Berlin Heidelberg 2013

As many of you have noticed, from this issue, Building Simulation journal made the first adjustment of its editorial board members. After five years of dedicated services, the following members decided not to serve the board any further:

James Axley, Yale University, USA

John Grunewald, Dresden University of Technology, Germany

Shuzo Murakami, Keio University, Japan

William Nazaroff, University of California at Berkeley, USA

Needless to say, the success of the Journal would not be possible without the enthusiastic support and contribution of our board members. We give our highest regards to these members, and hope to receive their continuous support in the future.

Meanwhile, we are much honored to have the following world renowned experts to join the editorial board:

Qingyan Chen, Purdue University, USA

Richard Corsi, The University of Texas at Austin, USA

Tianzhen Hong, Lawrence Berkeley National Laboratory, USA

Madjid Madjidi, Ingenieurbüro Madjidi, Germany

Akashi Mochida, Tohoku University, Japan

Jianlei Niu, The Hong Kong Polytechnic University, Hong

Kong, China

Christoph Reinhart, Massachusetts Institute of Technology, USA

Wolfram Stephan, University of Nuremberg, Germany

Zhiqiang (John) Zhai, University of Colorado at Boulder, USA

New roster of the entire editorial board can be found from the printed issues and the Journal's website. On behalf of the editorial office and continuing board members, let me officially welcome their joining the board. We look forward to a joyful collaboration in many years ahead.

As the first international journal focusing on building simulation, our goal is to serve the broad readership that may benefit from our publications. Based on my and many others' observation, our journal has already started to make an impact in various aspects. Although, how to measure the degree of impact is (and will always be) a topic under much debate, most popular academic databases use the following formula to calculate the "Impact Factor (IF)" for a given year $Y$ :

$$
\text { Year } Y \text { impact factor }=C / P
$$

where, $C=$ the number of times that articles published in two preceding years (Years $Y-1$ and $Y-2$ ) were cited by indexed journals during year $Y$; $P=$ the total number of "citable items" published by that journal in two preceding years (Years $Y-1$ and $Y-2$ ).

If IF (no wrong spelling here) can be used as a proxy for the relative importance of a journal within its field, then it means that the more articles being cited in recent two years, the higher impact a journal would be.

Mathematics and indices try to make complicated things simple. Nevertheless, if we accept this measurement method, where does Building Simulation journal stand? In 2012, Building Simulation received the first IF of 0.815 after being included by Science Citation Index (SCI) of Thomson Reuters. Among all the SCI journals in the Construction and Building Technology category, Building Simulation was ranked 20/56 (or Quarter 2). Remember, our journal is just a five years old "baby", and many others have been "adults" for years!

E-mail: bsjournal@tsinghua.edu.cn 
In fact, we do have our own way to track how the Journal is performing, other than using the popular index. The number of submissions is steadily increasing, and the rejection rate has reached 53\% in 2012. Meanwhile, we try to keep the paper processing time as short as possible. To authors, this means short waiting time. To readers, this means accessing newest information in a timely manner. To our board members, reviewers, and journal office staff, this means much heavier work load.

The importance of building simulation has motivated substantial scientific research in the academic community. Building Simulation provides an important venue to present the results of such studies. And, of course, it is common to have scientific debates or discussions on various topics. In this issue, we publish a commentary article to previously published work, along with the reply from the original authors. We believe that this kind of discussion is a healthy way to better understand complex physical problems.

Please come and visit Building Simulation often. 